\title{
Coping with shorter days: Do phenology shifts constrain aphid fitness?
}

Jens Joschinski, Thomas Hovestadt, Jochen Krauss

Climate change can alter the phenology of organisms. It may thus lead seasonal organisms to face different day lengths than in the past, and the fitness consequences of these changes are as yet unclear. To study such effects we used the pea aphid Acyrthosiphon pisum as model organism as it has obligately asexual clones, which can be used to study day length effects without eliciting a seasonal response. We recorded life-history traits under short and long days both with two realistic temperature cycles with means differing by $2^{\circ} \mathrm{C}$. In addition we measured the population growth of aphids on their host plant Pisum sativum. We show that short days reduce fecundity and the length of the reproductive period of aphids. Nevertheless this does not translate to differences at the population level, because the observed fitness costs only become apparent late in the individual's life. As expected, warm temperature shortens the development time by 0.7 days $/{ }^{\circ} \mathrm{C}$, leading to faster generation times. We found no interaction of temperature and day length. We conclude that day length changes cause only relatively mild costs, which may not decelerate the increase in pest status due to climate change. 


\section{Coping with shorter days: Do phenology shifts constrain aphid fitness?}

Jens Joschinski ${ }^{1 *}$, Thomas Hovestadt ${ }^{2,3}$, Jochen Krauss ${ }^{1}$

${ }^{1}$ Department of Animal Ecology and Tropical Biology, Biocentre, University of Würzburg, D-97074 Würzburg, Germany

${ }^{2}$ Department of Animal Ecology and Tropical Biology, Field Station Fabrikschleichach, D- 96181 Rauhenebrach, Germany

${ }^{3}$ Department of Biology (TEREC), Ghent University,9000 Ghent, Belgium

*Corresponding author: Jens Joschinski

E-Mail Jens.Joschinski@uni-wuerzburg.de

Phone: $+49(0) 931 / 31-82922$

Fax. $0049(0) 931$ 31-84352

\section{Abstract}

Climate change can alter the phenology of organisms. It may thus lead seasonal organisms to face different day lengths than in the past, and the fitness consequences of these changes are as yet unclear.

To study such effects we used the pea aphid Acyrthosiphon pisum as model organism as it has obligately

4 asexual clones, which can be used to study day length effects without eliciting a seasonal response. We recorded

5 life-history traits under short and long days both with two realistic temperature cycles with means differing by $2^{\circ} \mathrm{C}$.

6 In addition we measured the population growth of aphids on their host plant Pisum sativum.

$7 \quad$ We show that short days reduce fecundity and the length of the reproductive period of aphids. Nevertheless

8 this does not translate to differences at the population level, because the observed fitness costs only become apparent

9 late in the individual's life. As expected, warm temperature shortens the development time by 0.7 days $/{ }^{\circ} \mathrm{C}$, leading

10 to faster generation times. We found no interaction of temperature and day length. We conclude that day length

11 changes cause only relatively mild costs, which may not decelerate the increase in pest status due to climate change. 


\section{Introduction}

Nearly all organisms need to cope with environmental heterogeneity and fluctuation;

14 showing a plastic response in the face of such heterogeneity can be beneficial. For example,

15 several species from the Daphnia complex (Cladocera) can grow a 'crown of thorns' in response

16 to predator pressure (Petrusek et al. 2009), and Daphnia magna allocates variable amounts of

17 energy to size and shape as adaptive induced response to predator presence (Rabus \& Laforsch

18 2011). Similarly, many plants increase their investment into defence when attacked by

19 herbivores (e.g. Agrawal 2011). These examples demonstrate how phenotypic plasticity can

20 affect fitness. One of the most important fitness traits is phenology (Chuine 2010; Helm et al.

21 2013), i.e., the timing of life cycle events. Plasticity in phenology can profoundly change the

22 ecology of a species, as it can alter the timing of critical life-history events and synchrony with

23 other trophic levels (Visser et al. 1998; Visser \& Holleman 2001). Thus phenological plasticity is

24 an important component of the ecology and evolution of species.

25 Phenotypic plasticity can not only be adaptive in temporally fluctuating environments,

26 but also prevent extinction in environments under directional change (Chevin et al. 2013). The

27 current rate of environmental change is likely unprecedented since 1400 years (IPCC WG I

28 2013), as the global surface temperature rises by $0.2^{\circ} \mathrm{C}$ per decade (Hansen et al. 2006). Climate

29 change modifies the onset and duration of seasons (Räisänen \& Eklund 2012), and many species

30 have already responded by shifting their phenology in the according direction (Rosenzweig et al.

31 2007). By adjusting phenology via plastic responses, organisms can possibly mitigate the

32 extinction risk imposed by climate change (Charmantier et al. 2008; Vedder et al. 2013), and

33 even profit from it (Bell et al. 2015). 
However, the evolution of phenotypic plasticity may be constrained by costs and limits

35 (DeWitt et al. 1998). For example, plasticity can be limited by tightly interacting species, which

36 may not shift their timing in synchrony. Among the best studied examples are great tit

37 populations which have lost synchrony with their caterpillar prey (Visser et al. 1998), and winter

38 moths which are no longer synchronous with their host (Visser \& Holleman 2001). We

39 hypothesize that another limit of plasticity is posed by the reduction in day length (photoperiod)

40 associated with a shift in phenology: First, activities of a diurnal species, e.g. foraging, can be

41 constrained by shorter days, if individuals live in a later time of the year. Secondly, photoperiod

42 is the most common cue to predict seasonal change (Saunders 2013). Photoperiodism is

43 commonly assumed to be based on the circadian clock (Bünning 1936; Saunders 2013), a

44 molecular clockwork which governs rhythmicity (Peschel \& Helfrich-Förster 2011). Thus we

45 hypothesize that altered day length conditions interfere with the (yet unresolved) interplay of

46 seasonal and circadian rhythmicity and hence affect phenotypic plasticity.

47 The effect of warming temperature on fitness is relatively well established. Within

48 physiological limits warmer temperature generally speeds up metabolic rates (Gillooly et al.

49 2001). Less researched, and potentially important in a changing climate, are interactions of day

50 length and temperature. We propose that warmer temperature results in faster growth during the

51 organism's active period, but higher energy expenditure during resting time. Hence, the effect of

52 temperature should depend on day length. Also, temperature might enhance the interference with

53 circadian timing, as the clockwork is not fully compensated for temperature changes (Saunders

54 2014). Thus, short day conditions may decrease insect fitness, whereas warm temperature should

55 enhance growth rates, and warming might enhance the fitness costs of short days. 
Aphids like Acyrthosiphon pisum (HARRIS) are well suited to study constraints of short

days. During summer A pisum reproduces clonally, establishing exponentially growing populations. Live-born nymphs have, however, little chance to survive sub-zero temperatures (Simon et al. 2002). Therefore, in many clones aphids give birth to a single generation of sexual morphs in autumn, which produce cold-resistant eggs to overwinter. In warmer climates this response to photoperiod is frequently lost, so asexual aphid morphs are active throughout the year (Simon et al. 2002). These differences in phenology within one species allow studying day length effects in a seasonal insect without actually inducing a photoperiodic response. Specifically we hypothesize, that

(1) Shorter day length constrains aphid performance and reduces population growth.

(2) Warm temperature causes quicker generation cycles and faster population growth.

(3) Temperature and day length interact, so that the positive effects of an increase in ambient temperature decline with shorter day length.

We therefore expect fitness costs under short-day conditions compared with long-day conditions, and possibly the lowest fitness under short days combined with warm conditions.

\section{Materials and Methods}

To test for constraints of phenotypic plasticity, we carried out experiments with an asexual clone of the aphid A. pisum in four climate chambers at the individual as well as at the population level. We measured population growth on whole plants of Pisum sativum (L.), and life history data of individuals raised on cut leaves of $P$. sativum.

\section{Day length and temperature settings}


We used four identical climate chambers (Sanyo/Panasonic MLR-H series), in which we

80 applied two realistic temperature settings with sinusoid day/night cycles, ranging from $12-23^{\circ} \mathrm{C}$

$81\left( \pm 1^{\circ} \mathrm{C}\right)$ and from $14-25^{\circ} \mathrm{C}\left( \pm 1^{\circ} \mathrm{C}\right)$, and two day length regimes with day length of 12:12 $\mathrm{LD}$ and

82 16:8 LD (Fig. 1), using 40W fluorescent lamps. The temperature differed between the light

83 treatments at dawn and dusk, but this difference in light sums is only $1.2 \%$. Treatments were

84 exchanged weekly, because the maximum light intensities varied between chambers from 13,000

$85-21,000$ lux. Because development and reproductive period lasted four weeks, all treatments

86 received the same light sum $[\mathrm{lux} * \mathrm{~h}]$ over this period. The lower temperature settings in the

87 experiment approximately reflect naturally occurring temperatures in Würzburg, southern

88 Germany, during summer solstice $\left(12-22^{\circ} \mathrm{C}\right)$ and during beginning of September $\left(11-22^{\circ} \mathrm{C}\right.$; data

89 from Deutscher Wetterdienst, http://www.dwd.de/). The higher temperature settings simulate

90 climate change with moderately increased mean temperature of $2^{\circ} \mathrm{C}$, which ranges between the

91 SRES B1 and B2 marker scenario projections for 2099 (IPCC WGIII 2000). We are aware that

92 this is a conservative estimate; we nevertheless used this low difference of means, so that we did

93 not confound the results by exceeding the physiological optimum of the pea aphid.

95 Study organisms

96 Due to its fast population growth and its properties as virus vector, Acyrthosiphon pisum

97 (HARRIS, Aphididae) is a pest in agriculture, which is distributed throughout northern Europe,

98 North America and New Zealand (Blackman \& Eastop 2000). Acyrthosiphon pisum feeds on

99 legume crops such as pea (Pisum sativum L.) and bean (Vicia faba L.), and does not switch hosts

100 in autumn. The aphid clone L1_22, an asexual green alfalfa biotype, was kindly provided by Grit 
101 Kunert (MPI Jena). The known asexuality of the clone has been confirmed by providing an 8:16

$102 \mathrm{LD}$ rhythm at $10^{\circ} \mathrm{C}$ for four generations.

103 Pisum sativum L. is a suitable host plant for A. pisum, and agricultural plants are frequently

104 attacked by aphids (Blackman \& Eastop 2000). We used the breed 'Kleine Rheinländerin'

105 (Bingenheimer Saatgut, Echzell, Germany), which grows to $40 \mathrm{~cm}$, for all experiments.

107 Performance of individual aphids

108 To detect day length and temperature effects on the individual performance of aphids, we 109 placed 20 adult apterous, asexual aphids per climate chamber $(20 \times 4=80)$ singly in plastic tubes

$110(8 \times 3.5 \mathrm{~cm})$, and used their first born nymphs (termed first generation) as new focal individuals

111 for further measurement. These first-generation nymphs were fed every second day with one cut

112 leaf each, and we recorded development time, length of reproductive period, post-reproductive

113 period and life span. We used cut leaves like Meister et al. (2006) to exclude differences in food

114 quality, as a living host plant can be expected to fix more carbon under long day conditions. We

115 counted and discarded newly born nymphs daily (thus measuring daily fecundity and lifetime

116 reproductive output of each focal animal). In order to test for maternal effects in a second

117 generation and to confirm the loss of sexuality in the clone we retained one early-born nymph

118 per focal aphid after 11-13 days. Additionally, we retained one late-born nymph after 29-31

119 days, because we expected the maternal effects to intensify as the adult ages. We raised all

120 aphids of the second generation under the same conditions $\left(16: 8 \mathrm{LD}, 22^{\circ} \mathrm{C}\right.$ and $60 \%$ humidity),

121 so that maternal effects could be distinguished from direct effects of day length and temperature.

122 These second generation aphids were fed with fresh plant material every second day, and life

123 history parameters were also recorded every second day. 
125 Rheinländerin') per week with two plants per pot $\left(11 \times 11 \mathrm{~cm}\right.$, filled with Einheitserde ${ }^{\circledR}$ classic

126 soil, Einheitserdewerk Hameln $\mathrm{GmbH}$, Sinntal, Germany) over six weeks at $22^{\circ} \mathrm{C}, 16: 8 \mathrm{LD}$ and

$12760 \%$ humidity, so that 2-3 week old plant material (approximate $\mathrm{BBCH}$ growth stage 14-15) was

128 available over the whole course of the experiment. Pea plants grow pinnate compound leaves

129 with morphologically different stipules. We fed four leaflets from the same leaf compound (the

130 youngest which had completely unfolded leaflets), but excluded the basal stipulate leaves. If

131 there was not enough plant material available, we fed the aphids with plant material of two leaf

132 compounds of similar age. The four leaflets were randomly distributed over the four treatments

133 to ensure that all treatments received the same plant quality. We used the same plant no more

134 than twice in order to avoid induction of defense. The plants were always raised at $22^{\circ} \mathrm{C}$ and in a $135 \quad 16: 8$ LD cycle.

136 Altogether 80 individuals of the aphid A. pisum were used in the experiment. Nine aphids

137 died before reaching reproductive age, and six individuals (7.5\%; five under cold, short day and

138 one under warm, short day treatment) developed into alate (winged) virginoparous morphs. The

13915 deceased or winged individuals were excluded from further analysis. A further ten aphid

140 individuals were accidentally killed as adults, which reduced the number of replicates to 55

141 aphids for the traits fecundity, reproductive period, post-reproductive period and life span.

\section{Population experiment}

To detect the effects of day length and temperature on population demography, we sowed

14560 pea plants into $11 \times 11 \mathrm{~cm}$ square pots filled with a peat-based substrate (Einheitserde ${ }^{\circledR}$ classic,

146 Einheitserdewerk Hameln GmbH, Sinntal, Germany). The plants were watered from above 
147 during the first week and from below (using felt mats) thereafter in four trays with 15 plants

148 each. We kept all plants in a walk-in climate chamber with $22^{\circ} \mathrm{C}$ at $16: 8 \mathrm{LD}$ and $60 \%$ humidity

149 and watered five times per week. After 18 days we fixed each plant with raffia fibres to $50 \mathrm{~cm}$

150 wood sticks. After 25 days 12 plants from each tray were evenly distributed over the four climate

151 regimes (48 plants in total), and the position within each chamber fully randomized. Following

152 one week of acclimation we established aphid populations by placing 10 individuals of adult

153 apterous (wingless) asexual morphs on each individually bagged plant, using micro-perforated

154 plastic bags $(255 \times 700 \mathrm{~mm}, 0.5 \mathrm{~mm}$ perforations, Baumann Saatzuchtbedarf, www.baumann-

155 saatzuchtbedarf.de). To accommodate for climate chamber differences we exchanged treatments

156 between chambers weekly. We estimated population size weekly by counts of alate (winged) and

157 apterous adults and nymphs (judged by the visibility of the cauda and size differences) over the

158 course of four weeks on the living plants (BBCH growth stages approximately 16-19). To

159 control the effect of heat stress on the plants we distributed 24 aphid-free, 23 days old plants over

160 the four chambers to observe plant responses to the artificial climate over four weeks.

161

$162 \underline{\text { Statistics }}$

163 We used R version 2.15.2 (R Core Team 2012) for all analyses. On the individual level,

16465 out of 80 aphids were used to assess development time, and 55 for the remaining variables

165 (length of reproductive period, length of post-reproductive period, life span and fecundity). We

166 tested effects of day length, temperature and their interactions as main factors in two-way

167 ANOVAs on all of those parameters except fecundity. The latter we used to construct a Leslie

168 Matrix to yield the theoretical population rate of increase $r_{t}$ and the reproductive values of each

169 age cohort (Leslie 1945). We used a Leslie matrix, because averaged daily fecundity (as for 
170 example used by Meister et al. 2006) does not account for skews in the fecundity curve, which

171 cause shorter generation times and alter growth rate projections. In particular, late-born offspring

172 add very little to population growth compared to early-born offspring, and the true fitness costs

173 may be over- or underestimated. We used the estimates of $r_{t}$ in a two-way ANOVA to also test

174 for effects of day length and temperature. At the population level, we calculated the weekly

175 population growth rates $r_{1}, r_{2}$ and $r_{3}$ on 48 plants, as $\left(N_{x} / N_{x-1}\right)$, using the aphid number $N$ at week

$176 \mathrm{x}$, and the daily growth $\operatorname{as~}_{\mathrm{x}_{\mathrm{x}}}^{\wedge}(1 / 7)$. We compared the rates of increase, i.e. $\log$ (growth rates), in

177 two-way ANOVAs as before. Because a temperature gradient existed within the climate

178 chambers, the position within chambers had a significant effect for nymphal development and $r_{t}$.

179 However, as the position effect was in the same direction as the effect of temperature and did not 180 qualitatively change the results, we omitted it from analysis.

181

182

183

\section{Results}

185 Life history traits of individual aphids

186 In our experiment aphids developed on average within $10.7 \pm 0.2$ days and warm

187 temperature shortened the development time significantly (Fig. 2, Table 1, Table 2). The length

188 of the reproductive period (Fig. 2, Table 1) and the fecundity of aphids (Fig. 3, Table 1)

189 depended solely on day length. Aphids raised under short-day conditions reproduced about 3

190 days (14\%) less, and produced 22\% fewer nymphs (Table 2). The post-reproductive period

191 ranged from 5.0 \pm 0.6 (warm, long) to $9.8 \pm 1.3$ (cold, short) days, and was elongated by a

192 reduction of day length and of temperature (Fig. 2). Overall, warm temperature shortened the 
193 total life span, i.e. the sum of development time, reproductive and post-reproductive period. Even

194 though the food quality was sufficient for full development (including the post-reproductive

195 period) of all focal aphids in the first generation, the second generation suffered high mortality

196 rates (34\%) and reduced offspring numbers (to $0-30 \%) .73$ out of 75 surviving adults of the

197 second generation reproduced and no males were observed; so we confirm that the focal aphids

198 did not switch from asexual to sexual offspring. The theoretical population rates of increase $r_{t}$

199 (based on Leslie matrices) differed significantly between temperature regimes, but were

200 independent of day length (Fig. 4a). The reproductive values of the last three days of

201 reproduction were on average 1.56 , which is $9.7 \%$ of the maximum reproductive value (16.99).

202 The average growth rate was below the growth rate of the population experiment (see next

203 section), possibly because the cut leaves do not provide enough phloem pressure. 204

205 Fitness costs on the population level

206 In the population experiment, about $10 \%$ of the observed aphids were adults, and $0 \%$ (in

207 the first two weeks) to $13 \%$ (in the third week) of the adults were winged. Adult/nymph ratios

208 and winged/wingless ratios never varied significantly among treatments (all $\mathrm{p}>0.1$ ), so

209 differences in wing induction patterns are unlikely to have affected our results. Aphid density

210 (sum of nymphs, winged and wingless aphids) increased exponentially over the first two weeks,

211 with a weekly growth of about one order of magnitude (Fig. 4b). After two weeks aphid densities

212 were higher in the warm treatment $(1027 \pm 101$ aphids) than in the cold treatment $(668 \pm 42$

213 aphids), but not significantly affected by day length (Table 1). In week three the exponential

214 growth ceased, and during weeks three and four most plants died and aphid densities declined, 
215 especially in the warmer treatments. Control plants without aphids did not show any signs of heat

216 stress and were healthy throughout the experiment.

217

\section{Discussion}

219 Plasticity in phenology likely helps to make use of novel climate conditions and to extend

220 the asexual season, which may increase the pest status of aphids (Bell et al. 2015). However, the

221 novel day length conditions under which the animals live may be non-optimal to the organism,

222 and thus reduce the advantage of plasticity. Our results show that a $2^{\circ} \mathrm{C}$ increase in temperature

223 accelerates development and increases the population growth in an asexual aphid clone, but does

224 not alter the individual reproductive period or fecundity. In contrast to increased temperature a

225 shorter day length reduced the length of the reproductive period by $14 \%$ and fecundity by $22 \%$,

226 but did not significantly affect development time or life span.

228 Day Length

In our experiment day length alters fecundity and length of the reproductive period and

230 aphids suffer under short- day environments from reduced reproduction.

231 Even though variation in phenological traits is commonly regarded as phenotypic

232 plasticity (Charmantier et al. 2008; Vitasse et al. 2010; Vedder et al. 2013), the

233 microevolutionary costs and limits of plasticity (sensu DeWitt et al. 1998) in phenology have to

234 our knowledge never been measured. Phenotypic plasticity in phenology often relies on day

235 length (photoperiod) as cue, and our study is the first that demonstrates fitness costs linked to

236 short days in insects. On living plants aphids exhibit circadian rhythmicity and seem to be day-

237 active (Eisenbach \& Mittler 1980; Hodgson \& Lane 1981; Cortes et al. 2010), which offers - in 
238 agreement with the hypothesis outlined in the introduction - a tentative explanation for the

239 observed fitness loss under short days. Further studies will need to verify the diurnality

240 independent of host plants, and to measure phloem consumption under long and short days.

241 Photoperiod may also have a less direct effect on fitness, as its measurement may be

242 based on the circadian clock (Bünning 1936), an endogenous time-keeping mechanism which

243 relies on two cyclically expressed protein complexes, PERIOD/TIMELESS and

244 CLOCK/CYCLE (Peschel \& Helfrich-Förster 2011). Interference among seasonal rhythm and

245 circadian clock seems reasonable, though this hypothesis is still under debate (Danks 2005;

246 Kostal 2011). Hence shortening day length may not only affect the time available, but also its

247 correct measurement. So far, relatively little is known about the circadian rhythm of aphids, but

248 with the recent identification of the clock genes in aphids (Cortes et al. 2010), further progress

249 can be expected.

250 On the population level we did not detect effects of day length on fitness. Our calculation

251 based on Leslie matrices indicates that short day length does not significantly dampen population

252 growth, because the additional offspring produced under long days are born rather late in the

253 adults' life (c.f. Fig. 2); thus only life stages with little reproductive value are affected.

254 Consequently, substantial costs of shortened day length are not observed in our population

255 experiment. We thus conclude that the observed reduced reproduction does not impede 256 population growth.

\section{Temperature}

As expected, we found that warmer temperature shortens the life cycle of aphids. Because

260 the quicker life cycle leads to faster population growth both in our Leslie calculations and on real 
261 plants, climate change with increased mean temperatures should increase the pest potential of 262 aphids (Bell et al. 2015). Presumably warmer temperature acts on metabolic rates, as is well 263 established for insects (Gillooly et al. 2001). Temperature did, however, not change fecundity or 264 the length of the reproductive period over the measured range, and thus warm temperature per se 265 does not affect an individual's condition. This contradicts studies of temperature on the condition 266 of A. pisum by Campbell \& Mackauer (1977) and Kaakeh \& Dutcher (1993), but supports the 267 results of Kilian \& Nielson (1971). On a different aphid species, Rispe et al. (1996) also detected 268 no general effect of temperature on fecundity, but large variation among clones. Clonal variation 269 also explains differences between the cited experiments.

Because variability in temperature will likely increase due to climate change (Solomon et al. 2007), we included diurnal cycles in our design. Due to the nonlinear shape of the growth rate 272 curve, variability should increase the growth rate as long as it is below the optimum (Estay et al. 2013). Several studies on other clones indicate that the physiological optimum of A.pisum lies beyond $20^{\circ} \mathrm{C}$, and decreases only at temperatures higher than $25^{\circ} \mathrm{C}$ to $30^{\circ} \mathrm{C}$ (Kenten 1955; Kilian \& Nielson 1971; Campbell \& Mackauer 1977; Kaakeh \& Dutcher 1993; Rispe et al. 1996). Our treatments lie with 17.5 and $19.5^{\circ} \mathrm{C}$ below the reported optimum, so one would expect a larger effect of an increase in mean temperature on reproductive traits in our experiment compared to experiments applying constant temperatures. However, this hypothesis was not supported by our experiment. Kilian \& Nielson (1971) and Kaakeh and Dutcher (1993) recorded with constant temperatures around similar means $\left(15 / 20^{\circ} \mathrm{C}\right)$ a shortening of development time by 0.7 and 1.2 281 days $/{ }^{\circ} \mathrm{C}$, respectively. These values are largely in line with those in our experiment, where the 282 onset of reproduction shifted by 0.7 days $/{ }^{\circ} \mathrm{C}$. We found however some effect of temperature 283 variability on longevity, because in contrast to Kilian and Nielson (1971), in our study life span 
284 decreased under long days by 1.4 days $/{ }^{\circ} \mathrm{C}$. Possibly, our clone is adapted to colder temperature,

285 so that the maximum temperatures of $25^{\circ} \mathrm{C}$ stressed the aphids and caused a hazard. Therefore

286 higher temperature variability may decrease, not increase, aphid performance.

287

288

289

290

291

292

293 Conclusion

294

295

296

297

298

299

300

301

302

303

304

305

306 changing climate.

Contrary to our hypothesis that temperature has opposing effects at day and night, we

found no interaction of day length and temperature. We hence conclude that day- and night time temperatures have similar effects on aphid fitness and impose physiological constraints only by generally affecting the aphid metabolism.

We show that a shorter photoperiod reduces reproduction in obligately asexual aphids.

Consequently, the aphids' potential benefits following from global change are reduced, as temperature increase may lead to novel day length-temperature correlations. If the fitness decline has its roots in physiological constraints, our results may be extrapolated to any day-active insect species. However, these side-effects of phenotypic plasticity were not detected at the population level, because they affect only late fitness components in the individual's life. We further show that warm temperatures increase aphid growth by shortening development, but neither reduce individual reproduction, nor do they modulate the effect of short day length. Taken together, we conclude that novel light : temperature relations do not suppress the pest potential of aphids in a

Acknowledgements 
Bahlai and two anonymous reviewers for useful comments on the manuscript.

\section{References}

Agrawal AA. 2011. Current trends in the evolutionary ecology of plant defence. Functional Ecology 25:420-432. DOI: 10.1126/science.1060701.

314

315

316

317

318

319

320

321

322

323

324

325

326

327

328

329

330

331

332

333

334

335

336

337

338

339

340

341

342

343

344

345

346

Bell JR, Alderson L, Izera D, Kruger T, Parker S, Pickup J, Shortall CR, Taylor MS, Verrier P, and Harrington R. 2015. Long-term phenological trends, species accumulation rates, aphid traits and climate: five decades of change in migrating aphids. Journal of Animal Ecology 84:21-34. DOI: 10.1111/1365-2656.12282

Blackman RL, and Eastop VF. 2000. Aphids on the world's crops. Chichester, England: John Wiley \& Sons.

Bünning E. 1936. Die endogene Tagesrhythmik als Grundlage der Photoperiodischen Reaktion (Endogenous daily rhythms as the basis of photoperiodism). Berichte der Deutschen Botanischen Gesellschaft 54:590-607.

Campbell A, and Mackauer M. 1977. Reproduction and population growth of the Pea Aphid (Homoptera: Aphididae) under laboratory and field conditions. The Canadian Entomologist 109:277-284. DOI: 10.4039/Ent109277-2.

Charmantier A, McCleery RH, Cole LR, Perrins C, Kruuk LEB, and Sheldon BC. 2008. Adaptive phenotypic plasticity in response to climate change in a wild bird population. Science 320:800-803. DOI: 10.1126/science.1157174.

Chevin L-M, Gallet R, Gomulkiewicz R, Holt RD, and Fellous S. 2013. Phenotypic plasticity in evolutionary rescue experiments. Philosophical Transactions of the Royal Society Series B: Biological Sciences 368. DOI: 10.1098/rstb.2012.0089.

Chuine I. 2010. Why does phenology drive species distribution? Philosophical transactions of the Royal Society of London Series B, Biological sciences 365:3149-3160. DOI: 10.1098/rstb.2010.0142.

Cortes T, Ortiz-Rivas B, and Martinez-Torres D. 2010. Identification and characterization of circadian clock genes in the pea aphid Acyrthosiphon pisum. Insect Molecular Biology 19:123-139. DOI: 10.1111/j.1365-2583.2009.00931.x. 
347
Danks HV. 2005. How similar are daily and seasonal biological clocks? Journal of Insect Physiology 51:609-619. DOI: 10.1016/j.jinsphys.2005.01.005.

DeWitt TJ, Sih A, and Wilson DS. 1998. Costs and limits of phenotypic plasticity. Trends in Ecology \& Evolution 13:77-81. DOI: 10.1016/S0169-5347(97)01274-3.

Eisenbach J, and Mittler TE. 1980. An aphid circadian rhythm: Factors affecting the release of sex pheromone by oviparae of the greenbug, Schizaphis graminum. Journal of Insect Physiology 26:511-515. DOI: 10.1016/0022-1910(80)90125-0.

Estay SA, Lima M, and Bozinovic F. 2013. The role of temperature variability on insect performance and population dynamics in a warming world. Oikos 123:131-140. DOI: 10.1111/j.1600-0706.2013.00607.x.

Gillooly JF, Brown JH, West GB, Savage VM, and Charnov EL. 2001. Effects of size and temperature on metabolic rate. Science 293:2248-2251. DOI: 10.1126/science.1061967.

Hansen J, Sato M, Ruedy R, Lo K, Lea DW, and Medina-Elizade M. 2006. Global temperature change. Proceedings of the National Academy of Sciences 103:14288-14293. DOI: 10.1073/pnas.0606291103.

Helm B, Ben-Shlomo R, Sheriff MJ, Hut RA, Foster R, Barnes BM, and Dominoni D. 2013. Annual rhythms that underlie phenology: Biological time-keeping meets environmental change. Proceedings of the Royal Society of London Series B: Biological Sciences 280. DOI: $10.1098 / \mathrm{rspb} .2013 .0016$.

Hodgson CJ, and Lane IR. 1981. Some effects of photoperiod on larviposition and fresh weightgain in Myzus persicae. Physiological Entomology 6:21-25. DOI: 10.1111/j.13653032.1981.tb00256.x.

IPCC WG I. 2013. Climate Change 2013: The physical science basis. Working Group I contribution to the Fifth Assessment Report of the Intergovernmental Panel on Climate Change. New York: Cambridge University Press.

IPCC WG III. 2000. Special report on emissions scenarios. Cambridge, U.K.: Cambridge University Press.

Kaakeh W, and Dutcher JD. 1993. Rates of increase and probing behavior of Acyrthosiphon pisum (Homoptera: Aphididae) on preferred and nonpreferred host cover crops. Environmental Entomology 22:1016-1021. DOI: 10.1093/ee/22.5.1016.

Kenten J. 1955. The Effect of photoperiod and temperature on reproduction in Acyrthosiphon pisum (Harris) and on the forms produced. Bulletin of Entomological Research 46:599624. DOI: $10.1017 / \mathrm{S} 0007485300039572$. 
392

393

394

395

396

397

398

399

400

401

402

403

404

405

406

407

408

409

410

411

412

413

414

415

416

417

418

419

420

421

422

423

424

425

426

427

428

429

430

431

432

433

434

435

436

Kilian L, and Nielson MW. 1971. Differential effects of temperature on the biological activity of four biotypes of the Pea Aphid. Journal of Economic Entomology 64:153-155. DOI: 10.1093/jee/64.1.153.

Kostal V. 2011. Insect photoperiodic calendar and circadian clock: Independence, cooperation, or unity? Journal of Insect Physiology 57:538-556. DOI: 10.1016/j.jinsphys.2010.10.006.

Leslie PH. 1945. On the use of matrices in certain population mathematics. Biometrika 33:183212. DOI: $10.2307 / 2332297$

Meister B, Krauss J, Härri SA, Schneider MV, and Müller CB. 2006. Fungal endosymbionts affect aphid population size by reduction of adult life span and fecundity. Basic and Applied Ecology 7:244-252. DOI: 10.1016/j.baae.2005.06.002.

Peschel N, and Helfrich-Förster C. 2011. Setting the clock - by nature: Circadian rhythm in the fruitfly Drosophila melanogaster. Febs Letters 585:1435-1442. DOI:

10.1016/j.febslet.2011.02.028.

Petrusek A, Tollrian R, Schwenk K, Haas A, and Laforsch C. 2009. A "crown of thorns" is an inducible defense that protects Daphnia against an ancient predator. Proceedings of the National Academy of Sciences 106:2248-2252. DOI: 10.1073/pnas.0808075106.

R Core Team. 2012. R: A language and environment for statistical computing. Vienna, Austria: R Foundation for Statistical Computing.

Rabus M, and Laforsch C. 2011. Growing large and bulky in the presence of the enemy: Daphnia magna gradually switches the mode of inducible morphological defences. Functional Ecology 25:1137-1143. DOI: 10.1111/j.1365-2435.2011.01840.x.

Räisänen J, and Eklund J. 2012. 21st Century changes in snow climate in Northern Europe: a high-resolution view from ENSEMBLES regional climate models. Climate Dynamics 38:2575-2591. DOI: 10.1007/s00382-011-1076-3.

Rispe C, Simon JC, and Pierre JS. 1996. Fitness comparison between clones differing in their ability to produce sexuals in the aphid Rhopalosiphum padi. Entomologia Experimentalis Et Applicata 80:469-474. DOI: 10.1111/j.1570-7458.1996.tb00961.x.

Rosenzweig C, Casassa G, Karoly DJ, Imeson A, Liu C, Menzel A, Rawlins S, Root TL, Seguin B, and Tryjanowski P. 2007. Assessment of observed changes and responses in natural and managed systems. In: Parry ML, Canziani OF, Palutikof JP, van der Linden PJ, and Hanson CE, eds. Climate Change 2007: Impacts, adaptation and vulnerability contribution of Working Group II to the Fourth Assessment Report of the Intergovernmental Panel on Climate Change. Cambridge, UK: Cambridge University Press, 79-131. 
Saunders DS. 2013. Insect photoperiodism: Measuring the night. Journal of Insect Physiology 59:1-10. DOI: 10.1016/j.jinsphys.2012.11.003.

Saunders DS. 2014. Insect photoperiodism: Effects of temperature on the induction of insect diapause and diverse roles for the circadian system in the photoperiodic response. Entomological Science 17:25-40. DOI: 10.1111/ens.12059.

Simon J-C, Rispe C, and Sunnucks P. 2002. Ecology and evolution of sex in aphids. Trends in Ecology \& Evolution 17:34-39. DOI: 10.1016/s0169-5347(01)02331-x.

Solomon S, Qin D, Manning M, Chen Z, Marquis M, Averyt KB, Tignor M, and Miller HL. 2007. Climate Change 2007: The physical science basis. Contribution of Working Group I to the Fourth Assessment Report of the Intergovernmental Panel on Climate Change. Cambridge: Cambridge University Press.

Vedder O, Bouwhuis S, and Sheldon BC. 2013. Quantitative assessment of the importance of phenotypic plasticity in adaptation to climate change in wild bird populations. PLoS Biology 11.DOI: 10.1371/journal.pbio.1001605.

Visser ME, and Holleman LJM. 2001. Warmer springs disrupt the synchrony of oak and winter moth phenology. Proceedings of the Royal Society of London Series B: Biological Sciences 268:289-294. DOI: 10.1098/rspb.2000.1363.

Visser ME, Noordwijk AJv, Tinbergen JM, and Lessells CM. 1998. Warmer springs lead to mistimed reproduction in great tits (Parus major). Proceedings of the Royal Society of London Series B: Biological Sciences 265:1867-1870. DOI: 10.1098/rspb.1998.0514.

Vitasse Y, Bresson CC, Kremer A, Michalet R, and Delzon S. 2010. Quantifying phenological plasticity to temperature in two temperate tree species. Functional Ecology 24:12111218. DOI: $10.1111 / \mathrm{j} .1365-2435.2010 .01748 . x$. 


\section{Table $\mathbf{1}$ (on next page)}

ANOVA tables testing for day length and temperature effects on aphid life history traits. Significant effects are shown in bold. 


\begin{tabular}{|lllll|}
\hline Response variable & Factor & F & df & p (<F) \\
\hline \multirow{3}{*}{ Development time } & Temperature & 23.62 & 3,64 & $<\mathbf{0 . 0 0 1}$ \\
& Day length & 0.10 & 3,64 & 0.759 \\
& Temp x day length & 2.01 & 3,64 & 0.162 \\
\hline \multirow{3}{*}{ Reproductive period } & Temperature & 0.27 & 3,54 & 0.603 \\
& Day length & 6.98 & 3,54 & $\mathbf{0 . 0 1 1}$ \\
& Temp x day length & 0.22 & 3,54 & 0.643 \\
\hline \multirow{2}{*}{ Post-reproductive } & Temperature & 6.36 & 3,54 & $\mathbf{0 . 0 1 5}$ \\
period & Day length & 6.22 & 3,54 & $\mathbf{0 . 0 1 6}$ \\
& Temp x day length & 0.11 & 3,54 & 0.747 \\
\hline \multirow{3}{*}{ Life span } & Temperature & 9.24 & 3,54 & $\mathbf{0 . 0 0 4}$ \\
& Day length & 0.33 & 3,54 & 0.567 \\
\hline \multirow{3}{*}{ Total fecundity } & Temp x day length & 1.22 & 3,54 & 0.274 \\
\hline Remperature & 1.33 & 3,54 & 0.253 \\
\hline trate of increase & Day length & 12.84 & 3,54 & $<\mathbf{0 . 0 0 1}$ \\
derived from life- & Temp x day length & 2.70 & 3,54 & 0.107 \\
history traits) & Day length & 6.90 & 3,54 & $\mathbf{0 . 0 1 1}$ \\
\hline \multirow{2}{*}{ Population rate of } & Temp x day length & 2.95 & 3,54 & 0.773 \\
increase & Temperature & 4.92 & 3,41 & 0.092 \\
\hline & Day length & 0.04 & 3,41 & 0.032 \\
& Temp x day length & 0.54 & 3,41 & 0.465 \\
\hline
\end{tabular}




\section{Table 2 (on next page)}

Effect sizes of the four day length/temperature treatments on aphid life history traits. 


\begin{tabular}{|llllll|}
\hline Response variable & & \multicolumn{2}{l}{ Short day } & \multicolumn{2}{l|}{ Long day } \\
\hline Development time [days] & Low temp & 11.6 & $( \pm 0.2)$ & 11.2 & $( \pm 0.3)$ \\
& High temp & 9.7 & $( \pm 0.3)$ & 10.2 & $( \pm 0.3)$ \\
\hline Reproductive period [days] & Low temp & 19.7 & $( \pm 1.4)$ & 22.2 & $( \pm 0.8)$ \\
& High temp & 18.5 & $( \pm 0.9)$ & 22.1 & $( \pm 1.4)$ \\
\hline \multirow{2}{*}{ Postreproductive period [days] } & Low temp & 9.8 & $( \pm 1.3)$ & 7.1 & $( \pm 1.0)$ \\
& High temp & 7.1 & $( \pm 0.8)$ & 5.0 & $( \pm 0.6)$ \\
\hline Life span [days] & Low temp & 41.1 & $( \pm 1.2)$ & 40.3 & $( \pm 1.4)$ \\
& High temp & 35.0 & $( \pm 1.1)$ & 37.4 & $( \pm 1.8)$ \\
\hline \multirow{2}{*}{ Total fecundity [nymphs] } & Low temp & 54.2 & $( \pm 4.7)$ & 77.7 & $( \pm 2.9)$ \\
& High temp & 56.5 & $( \pm 4.1)$ & 65.3 & $( \pm 5.5)$ \\
\hline Rt (rate of increase & Low temp & 0.23 & $( \pm 0.003)$ & 0.24 & $( \pm 0.004)$ \\
derived from life- history traits) & High temp & 0.26 & $( \pm 0.009)$ & 0.25 & $( \pm 0.010)$ \\
\hline Population rate of increase & Low temp & 0.24 & $( \pm 0.010)$ & 0.25 & $( \pm 0.017)$ \\
& High temp & 0.31 & $( \pm 0.012)$ & 0.29 & $( \pm 0.039)$ \\
\hline
\end{tabular}




\section{1}

Temperature settings of the climate chambers

Warm temperature settings for long day (solid lines, lower bar) and short day (dashed lines, upper bar) treatments. Mean temperatures of long and short day conditions do not differ. The temperature in the two low temperature treatments was overall $2^{\circ} \mathrm{C}$ lower (not shown).

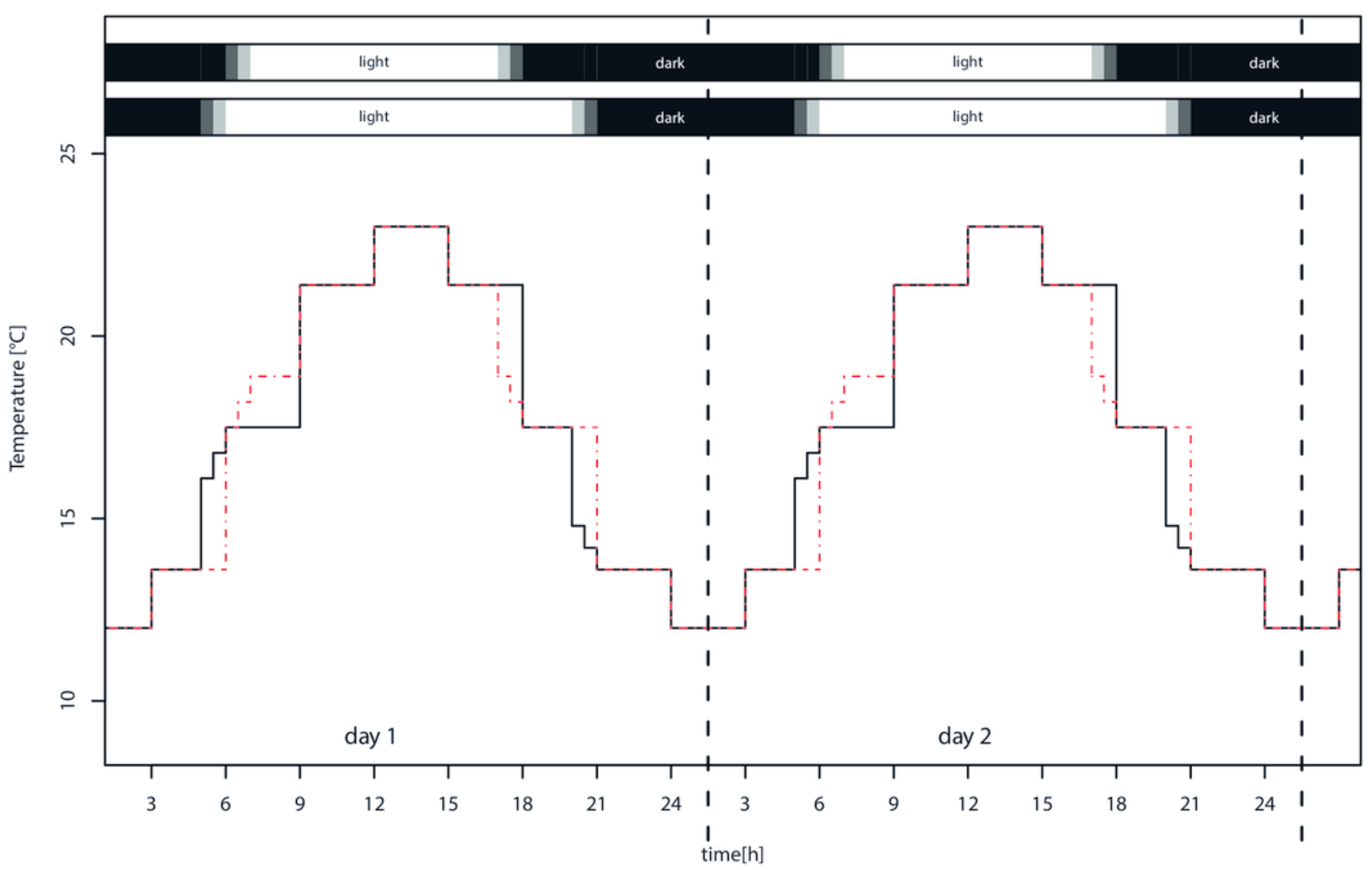




\section{2}

Life-history traits of individuals reared under different climate conditions.

The bars are aligned at the mean onset of reproduction (i.e. not left-aligned) to better distinguish temperature effects (on development) from day length effects (on reproduction). Bars indicate S.E. Lines with open circles indicate the timing of nymph production (expressed as daily contributions to total fecundity in \%). These curves form also the basis for the Leslie calculations (Table1, Table 2). Statistics see Table 1.

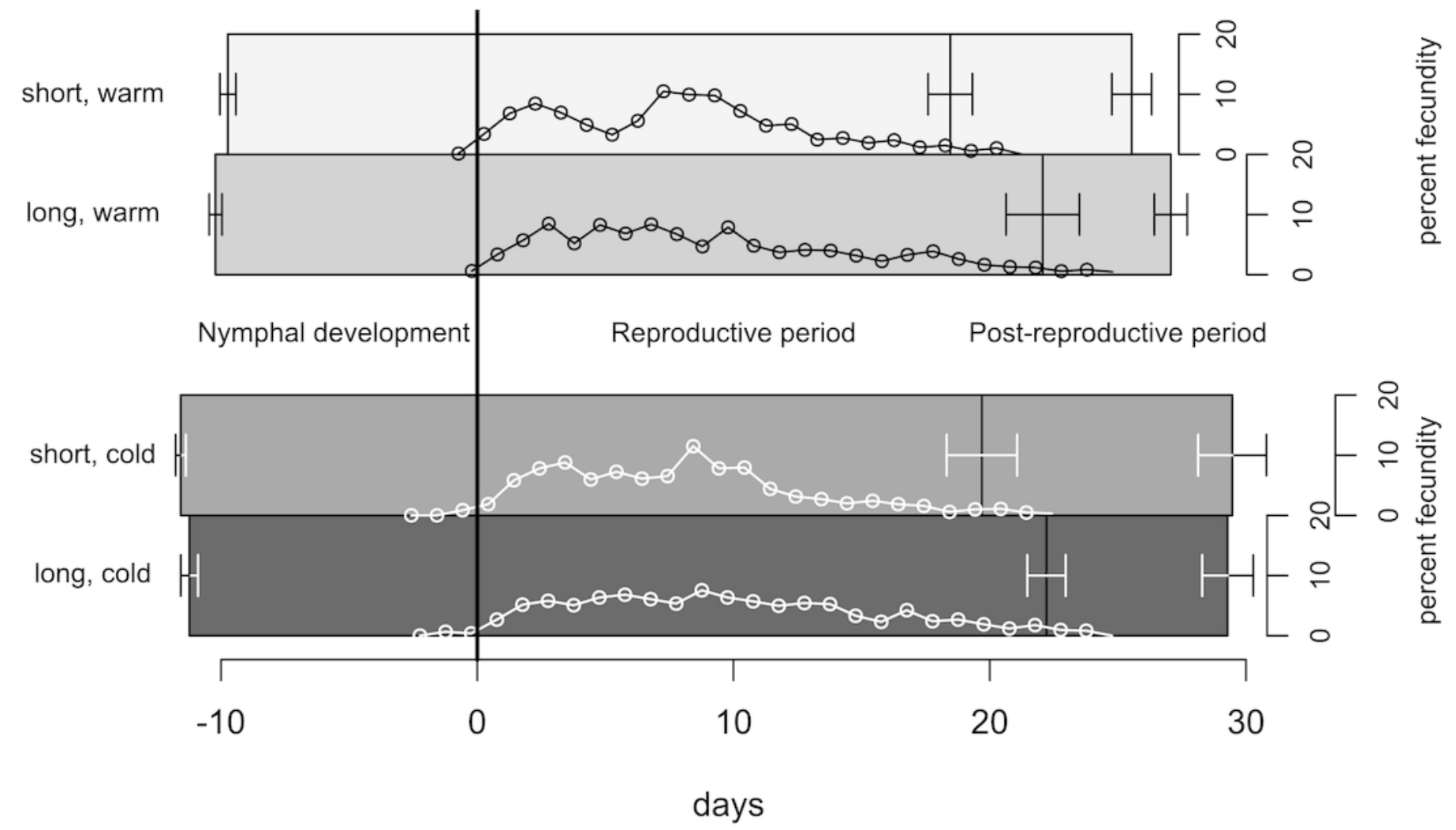


3

Cumulative fecundity as function of age of individuals reared under four climate conditions.

Bars indicate S.E. Statistics see Table 1. Sample size (N) declines over time, because the aphid mortality increases with age (c.f. Fig. 2).

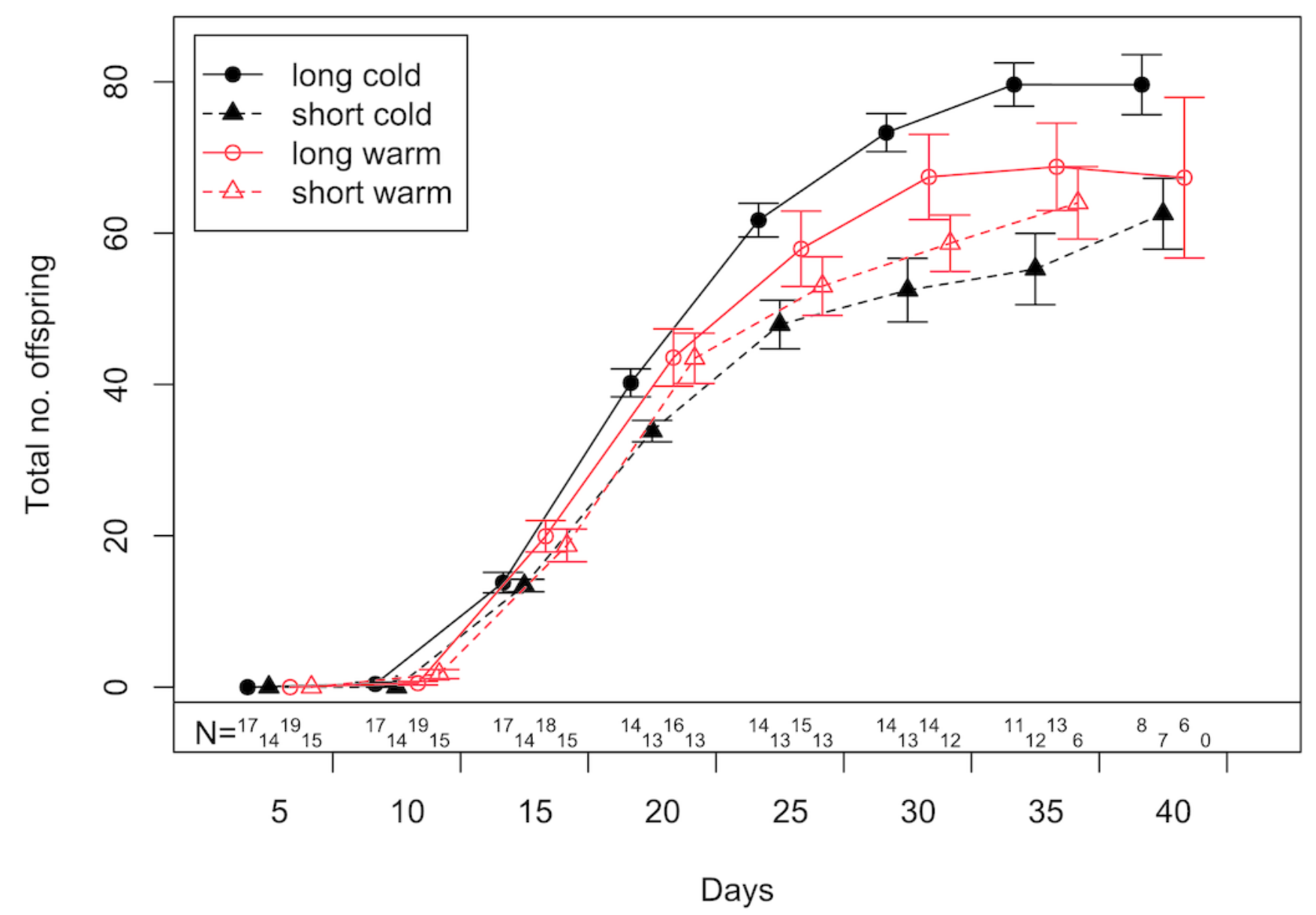




\section{4}

Growth rates of aphids under warm and cold conditions at $16: 8 \mathrm{~h}$ and $12: 12 \mathrm{~h}$ day length

A) Comparison of population rates of increase under warm vs. cold and under long day vs. short day conditions. Data is based on Leslie-matrices derived from individual life histories.

Bars indicate S.E. B) Population growth of aphids reared on whole plants. Dashed lines indicate the time when half of the plants died, presumably from increasing pest load. Statistics see Table 1. 


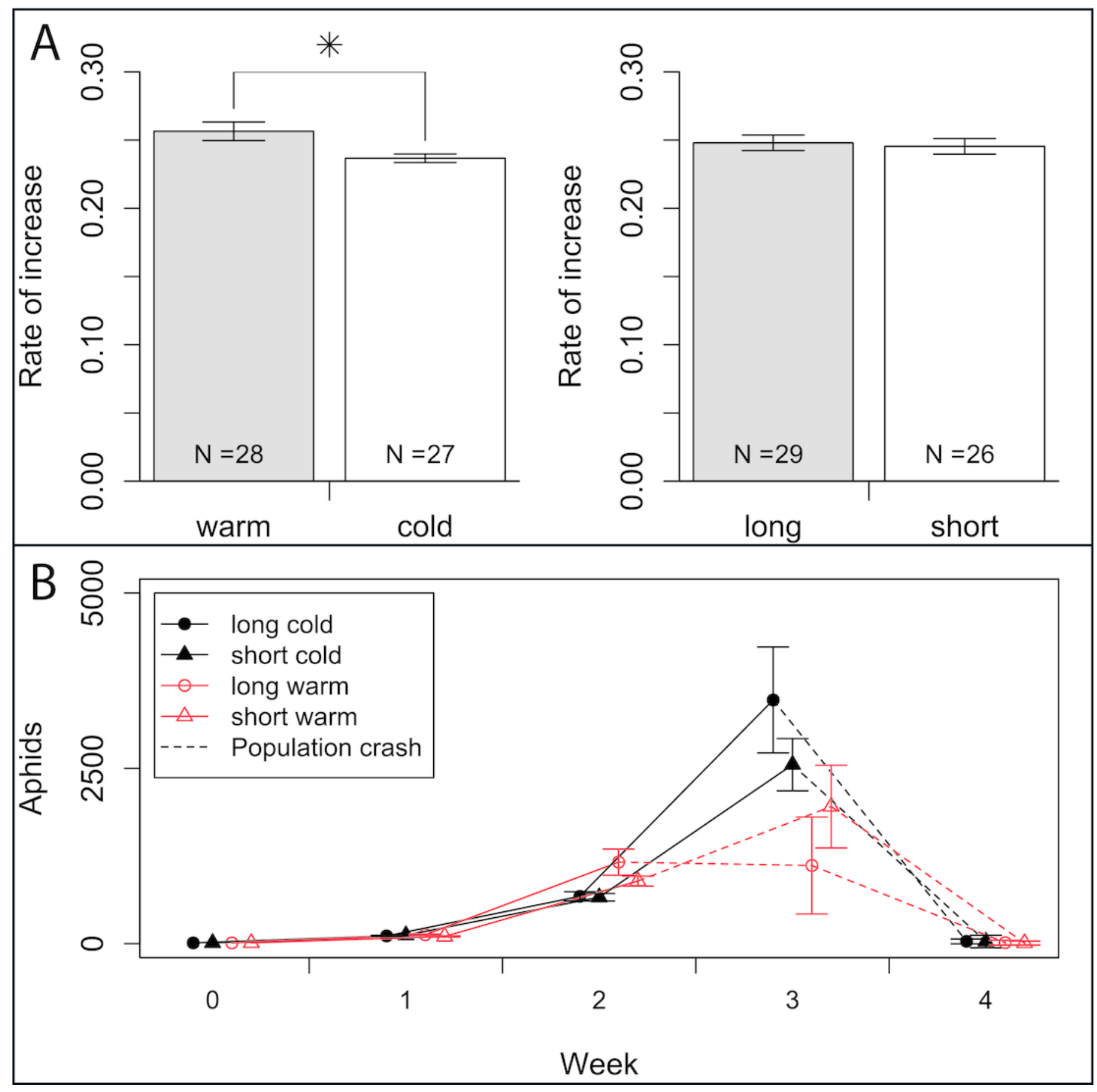

